\title{
TRABALHO, SOLIDARIEDADE SOCIAL E ECONOMIA SOLIDÁRIA
}

\author{
Jacob Carlos Lima e \\ André Ricardo de Souza
}

Neste artigo, analisamos a retomada do debate sobre solidariedade social, tendo como referências as transformações recentes nas relações de trabalho e o surgimento do movimento de economia solidária como proposta alternativa de ocupação e inclusão social. O ponto de partida é a reestruturação econômica a partir da década de 1970, a busca por redução de custos e flexibilização tanto das relações de trabalho, entendidas aqui em sua forma hegemônica, o assalariamento, quanto dos direitos incorporados ao contrato de trabalho. A condição salarial, de forma progressiva no século XX, passou a representar não apenas a forma de inclusão no mercado de trabalho, mas também o acesso a direitos sociais que garantiam a reprodução social dos trabalhadores, conferindo-lhes cidadania e representações simbólicas de cunho identitário, enquanto profissionais e membros de uma classe social. A fragilização desses direitos, com tentativas de desregulamentação das relações de trabalho, motivou o surgimento de movimentos de recuperação da solidariedade social para além do trabalho formalizado. 
No Brasil, a partir da mobilização de entidades sindicais, eclesiais e universitárias, constituiu-se o movimento nacional de economia solidária, propondo organizações coletivistas e democráticas, sobretudo cooperativas, de trabalho (Singer e Souza, 2000). Tal movimento incorporou distintas referências do debate sobre solidariedade, indo da perspectiva socialista e suas variações, ao chamado solidarismo cristão. Esse movimento surgiu em meados da década de 1990, e deu ensejo a políticas públicas em diversos níveis governamentais ${ }^{1}$, formalizando-se nacionalmente em 2003 com a criação da Secretaria Nacional de Economia Solidária (Senaes) no âmbito do Ministério do Trabalho e Emprego, como uma política alternativa de inserção social e ocupação voltada a pessoas excluídas do mercado formal de trabalho.

Iniciamos o texto com uma introdução ao conceito de solidariedade social vinculado à noção de trabalho e 140 direitos sociais, seguida por uma análise da constituição da chamada sociedade salarial e da solidariedade presente nas políticas do Estado de bem-estar social, discutindo seus referenciais teóricos; o corporativismo presente nas propostas de acesso aos direitos; e o Estado como mediador das relações capital-trabalho e agente da reprodução social. No item seguinte, recuperamos a discussão do solidarismo cristão que propunha o cooperativismo como terceira via entre o capitalismo e o socialismo, e por fim demonstramos o amálgama dessas referências na constituição da economia solidária no Brasil.

\section{Retomando o conceito de solidariedade}

Quando pensamos no conceito de solidariedade e sua vinculação com o trabalho na sociologia, nos remetemos, por

1 Destacam-se as administrações das prefeituras de Porto Alegre (1993-1996), Santo André (1997-2000) e do governo estadual do Rio Grande do Sul (19992002). 
um lado, a Marx e a questão da solidariedade de classe na formação de identidades coletivas, ação e mudança social. Por outro, aludimos a Durkheim e a construção da solidariedade orgânica, a partir da divisão social do trabalho, na perspectiva da construção de uma nova moral integrativa, decorrente da interdependência promovida pela especialização de funções.

A interdependência de funções proposta por Durkheim está presente na doutrina solidarista da III República Francesa, que buscava um meio-termo entre o individualismo exacerbado do liberalismo e as teorias coletivistas das lutas de classes, como o marxismo. Propunha a intervenção do Estado na economia e o estabelecimento de uma legislação social voltada aos trabalhadores, sendo a base das doutrinas corporativistas do século XX. Para Giddens (1998, p. 119), as propostas de associações profissionais reguladas pelo Estado, tal como defendido por Durkheim, teria afinidades, tanto com socialistas radicais, quanto com o solidarismo corporativista, no debate francês do período, sem que ele estivesse atrelado politicamente a estas propostas ${ }^{2}$.

Em um contexto anterior ao capitalismo industrial, podemos nos referir às solidariedades construídas pela família e pela comunidade que garantiam aos outsiders, vagabundos e andarilhos certa "proteção social", ou o reconhecimento do indivíduo como parte da comunidade, portanto, com direito a uma assistência básica em termos de alimentação e segurança. Segundo Castel (1998), a Igreja Católica regulou a mendicância no sentido do apoio à caridade cristã, mas estabeleceu normas restritas de valorização dos votos de pobreza que se restringiam à vida monástica. Na história do capitalismo, a normatização da pobreza atra-

2 Destacam-se entre os representantes do solidarismo francês no período o jurista Léon Duguit, Léon Bourgeois, autor de La solidarité (1896), E. Boutroux, autor de Essai d'une philosophie de la solidarité (1902), e C. Bouglé, com Le solidarisme, de 1924. Ver <cepp.iscsp.utl.pt cepp.pt.vu>. 
vés de leis específicas que reprimiam a "vagabundagem" estabeleceu as condições do assalariamento como relação social dominante, impondo aos trabalhadores a venda da força de trabalho num mercado que se constituía (Marx, 1975). Para Weber (2004), a ética protestante se contrapunha à caridade católica e aos que não trabalhavam, adequando-se ao espírito do capitalismo em formação.

A relação salarial, como forma de subordinação do trabalho ao capital, foi fortemente combatida pelo movimento operário em formação, que era a base do pensamento socialista no século XIX, tendo sido pensada como uma "nova forma de escravidão". Para o movimento socialista, as contradições desse processo, a posse privada dos meios de produção nas mãos do capitalista e o trabalho socializado das massas operárias, assim como o descompasso entre o desenvolvimento das forças produtivas e as relações sociais, levariam inevitavelmente à transformação social através da construção

142 de uma solidariedade de classe que, por sua vez, desencadearia um processo revolucionário, levando ao predomínio do trabalho sobre o capital, com a classe operária na liderança dessa transformação (Marx e Engels, 1968; Castel, 1998).

Até o último quartel do século XX, os processos organizacionais na indústria, a pesquisa sistemática e a aplicação do conhecimento científico na fábrica e as novas tecnologias colocaram novos problemas vinculados à divisão técnica do trabalho: fragmentação, intensificação e parcelização de tarefas; aprofundamento da separação entre trabalho intelectual e manual; necessidade de garantir aos trabalhadores condições mínimas de reprodução social como condição da produtividade industrial; além de questões motivacionais e ideológicas.

O impacto da Revolução Russa e as crises constantes do capitalismo levaram o Estado a intervir nas relações capital-trabalho, garantindo a reprodução social da força de trabalho em termos de saúde, educação e previdência social 
(Harvey, 1993). Essa intervenção, que ocorria de forma sistemática desde o final do século XIX, como resposta à crescente combatividade do movimento operário, se deu através de leis específicas que regulavam as jornadas de trabalho, o descanso remunerado, o trabalho infantil e de mulheres, adquirindo nova dimensão a partir dos anos 1920 e a implementação das proposições keneysianas-fordistas. A partir da Segunda Guerra Mundial, podemos nos referir, principalmente na Europa Ocidental e nos Estados Unidos, ao surgimento de formas de Estado de Bem-Estar Social, caracterizadas pelo pleno emprego e a extensão crescente dos direitos sociais vinculados à relação salarial (Harvey, 1993; Castells, 1999; Castel, 1998).

Essa mediação estatal respondeu, em grande medida, à luta dos trabalhadores nesses países por maiores conquistas, abrangendo redução da jornada de trabalho, seguro desemprego, férias remuneradas, assim como exigências da própria reprodução do capital em termos de trabalhadores escolarizados e qualificados, saudáveis etc. Mesmo restrito a um número reduzido de países, o Welfare State tornou-se modelo de desenvolvimento capitalista avançado, juntando democracia política com maior equidade social. Tornou-se também vitrine capitalista contra as privações políticas e materiais dos trabalhadores nas sociedades do bloco soviético no Leste Europeu, assim como modelo a ser seguido pelos países do terceiro mundo (Harvey, 1993).

Esse modelo foi confrontado pela crise que se seguiu a partir de 1973, com a reestruturação econômica e a implementação de políticas neoliberais: a internacionalização da produção e dos mercados; a redução das barreiras ao livre comércio; o enxugamento do papel do Estado com o corte dos investimentos sociais; e a mobilidade global do capital e do trabalho. Essa mobilidade foi propiciada pelas novas tecnologias informacionais e de transporte que revolucionaram todos os setores produtivos, provocando 
uma nova dinâmica temporal-espacial, facilitando o deslocamento da produção e a busca de menores custos (leia-se força de trabalho barata) em novos territórios, regiões e países (Castells, 1999). Em termos de trabalho, significou a redução expressiva dos trabalhadores ocupados pela adoção de novos modelos organizacionais e tecnológicos que propiciaram a diminuição da força de trabalho necessária. Eliminou postos de trabalho e aumentou potencialmente o desemprego ${ }^{3}$. A relação salarial passou a ser questionada por agregar custos referentes a taxas e contribuições sociais, em outros termos, à solidariedade social pressuposta nessas taxas de efeito redistributivo.

O desemprego estrutural resultante dessas transformações reacendeu o debate sobre a redução da jornada do trabalho - agora percebida como necessidade de redistribuição dos empregos existentes ${ }^{4}$. Provocou ainda a expansão do debate sobre o trabalho como meio para a inserção 144 social, seja através de emprego regular, seja de atividades remuneradas diversas, independente da relação salarial.

A reestruturação política e econômica do final do século XX - marcada pela crise ideológica com o fim do bloco socialista europeu, a ausência da perspectiva de revolução social, assim como de questionamento da classe social enquanto agente político - retomou a ideia de solidariedade como condição de inserção, interpretando os direitos presentes na condição salarial como direitos de cidadania a serem estendidos a todos os trabalhadores.

\footnotetext{
3 Existe uma farta bibliografia sobre esse processo, da qual podemos destacar os citados Castel (1998), Castells (1999), Braverman (1981), e outros, como Rifkin (1995) e Méda (1999).

4 No final dos anos 1970 e 1980, os trabalhadores discutiam a redução da jornada de trabalho para aumentar suas horas de lazer (Offe, 1989). Com a crise, o olhar sobre a redução da jornada mudou de enfoque. Alguns países europeus, como a França, reduziram a jornada de trabalho para 35 horas como forma de atenuar o desemprego, entretanto isso não evitou a migração de empregos para países onde o custo da força de trabalho é menor, na Europa oriental, Ásia, América Latina e norte da África.
} 


\section{Solidariedade social e condição salarial}

A obra Da divisão do trabalho social, de Durkheim (2010 [1930]), constitui um marco na análise da relação trabalho-solidariedade, através dos conceitos de solidariedade mecânica e solidariedade orgânica. A solidariedade orgânica influencia, ou pelo menos explica, se tivermos a Europa como referência, os debates a partir do final do século XIX sobre solidariedade corporativa, dos grupos e corporações profissionais. Isso irá marcar o ideário fascista posterior e a configuração keynesiana, que terão no trabalho e na relação salarial, que incorporam um conjunto de direitos sociais mediado pelo Estado, a base da solidariedade social (Paugam, 2011b [2007]).

Em Durkheim, é central a ideia de sociedade integrada nos moldes da solidariedade orgânica. Tal integração decorre não só da interdependência e complementaridade de funções dos indivíduos, através da divisão social do trabalho, mas também da existência de um padrão de estratificação considerado legítimo, assim como da distribuição populacional nas várias profissões. No pensamento durkheimiano, o contrário dessa integração, a anomia, decorre da ausência de harmonia entre o indivíduo e sua função, assim como do fato de as classes inferiores desejarem ter a vida das superiores. A moral que busca evitar tal situação e os conflitos decorrentes da distribuição desigual de recursos e poder é estabelecida pelas organizações que determinam regras de conduta ao conjunto dos indivíduos.

A moral é um fator crucial para a sustentação da sociedade industrial moderna e caberia aos grupamentos profissionais um papel destacado na sua efetivação. A importância das corporações não se deveria à sua dimensão econômica, mas, sim, moral. A solidariedade decorrente da divisão social do trabalho é validada mediante contratos sociais cuja base seria o princípio da cooperação (Oliveira, 2003). A organização social, dessa forma, pressupõe for- 
mas integrativas de indivíduos conforme uma ordem moral que garanta o bom funcionamento da sociedade (Paugam, 2011c). Em contraposição às contradições e ao conflito, presentes no pensamento marxista, a ideia de moral profissional teria um papel de integração, atenuando o risco de anomia, resultante de tais conflitos. As corporações e o Estado, de certa forma, regulariam a solidariedade social no sentido da extensão de direitos básicos aos trabalhadores. Podemos aproximar essa formulação à discussão posterior do Welfare State, pensado enquanto forma de solidariedade social, em suas diversas formas.

Esping-Andersen (1991, p. 101) propõe redefinir o Welfare State para além da cidadania social, envolvendo a garantia efetiva dos direitos sociais, com status legal e inviolável e que não se restringe a um desempenho, mas que implicaria uma "desmercadorização" do status do indivíduo frente ao mercado. Para ele, essa desmercadorização 146 introduzida pelos direitos sociais afrouxa o caráter de mercadoria presente na vinculação dos direitos às relações de trabalho. Tal processo implica a possibilidade de o indivíduo sobreviver sem depender do mercado. Entretanto, os diversos Welfare States decorrentes dessa desmercadorização se dão de formas diferenciadas.

No modelo liberal, predomina a assistência social, em que não é considerada a vinculação ao trabalho, mas a comprovação da pobreza, algo que resulta em benefícios reduzidos. Segundo esse autor, os benefícios são voltados a uma população de baixa renda, estigmatizada por uma ética do trabalho presente em sua atribuição, ou seja, para os que não trabalham.

O outro modelo, chamado de corporativista, dominante em países como Alemanha, França, Itália e Áustria, tem como referência a previdência social estatal e compulsória, com direitos amplos vinculados a contribuições oriundas do trabalho e emprego. São fortemente corporativistas, com 
direitos vinculados às diferenças de classes e status, fortemente influenciados pela Igreja Católica e a ideia de preservação da família tradicional.

Por fim, o modelo social-democrata que oferece benefícios iguais para todos, independentemente de contribuição anterior, com caráter universalista, direitos sociais estendidos à classe média e padrões de qualidade para atender essas classes, tendo como referência a Suécia e demais países nórdicos.

Para Paugam (2011b, p. XI-XII), os grupamentos profissionais exerceram ao longo do século XX uma influência considerável na regulação dos laços sociais, assim como na formação de uma consciência coletiva dos riscos sociais a serem assumidos coletivamente. Para ele, o Estado social francês se fundou no ideal de solidariedade social e, $a$ posteriori, poderíamos dizer que esse Estado seria um prolongamento normativo da análise durkheimiana.

As transformações econômicas e políticas a partir dos anos de 1970 colocaram em xeque a solidariedade social baseada na regulação estatal e na vinculação entre trabalho e os direitos sociais que a caracterizavam. A crise ideológica e a hegemonia de políticas neoliberais que se seguiram passaram a questionar e desmontar a regulação social pela qual a solidariedade se refletia nas políticas públicas voltadas aos trabalhadores assalariados. A sociedade salarial, descrita por Castel (2011), passou por um processo marcado pelo enxugamento da atuação estatal nas políticas sociais e pela fragilização das associações coletivas, como os sindicatos atuantes na defesa dos direitos dos trabalhadores.

O que veio a partir daí é conhecido: a abertura de mercados; a relocalização industrial; a busca das empresas por menores custos; a fragilização da relação salarial com a desvinculação de direitos e sua crescente individualização, dada a responsabilização do trabalhador pelo seu acesso; as mudanças organizacionais de cunho participativo, aumen- 
tando essa responsabilização; a intensificação do trabalho pelas novas tecnologias e técnicas organizacionais; a precarização das relações de trabalho, com o aumento de políticas de subcontratação; o aparecimento do desemprego estrutural. Nesse contexto, a relação salarial passa de algo a ser superado nas primeiras décadas do século XX para algo a ser recuperado, como uma busca de conquistas perdidas, numa nostalgia do Estado social e do pleno emprego, algo que sempre esteve restrito a um grupo seleto de países ${ }^{5}$.

A própria noção de trabalho é então questionada enquanto organizadora de sociabilidades e identidades sociais (Offe, 1989). O trabalho é confundido com relação salarial e o emprego percebido, em alguns momentos, como destinado ao desaparecimento. Esse debate se enfraqueceu diante da crise do ideário do mercado absoluto no século XXI, principalmente a partir da crise financeira mundial de 2008, que foi controlada exatamente pela 148 intervenção estatal. Embora tenham ganhado importância outras matrizes identitárias para além do trabalho (Hall, 2005), o fato é que este não deixou de ser um conceito sociológico fundamental.

O Estado reassumiu progressivamente o protagonismo na regulação social, mas isso não significou o retorno à situação anterior do que se convencionou chamar de anos gloriosos do Estado de bem-estar social. Temos algo diferente. A revolução permanente das forças produtivas, para utilizarmos o conceito marxista, continuou seu processo de queima dessas forças e criação de outras. O debate sobre a gestão do trabalho com formas participativas, atribuídas genericamente ao modelo japonês ou experiências pontuais na Suécia e na Itália dos anos 1960, se confronta agora com o "modelo chinês", ainda pouco estudado, mas que

\footnotetext{
5 Braga (2003) se refere à nostalgia do fordismo ao criticar o modelo da teoria da regulação, percebido como novo marco civilizatório.
} 
recupera formas tayloristas tradicionais, situação similar à presente nos processos de subcontratação e formação de redes empresariais. Misturam-se formas de organização do trabalho, a individualização - seja a taylorista, seja a participativa - com a incorporação de subjetividades do trabalhador enquanto qualificações requeridas. $\mathrm{O}$ assalariamento continua a forma dominante, como compra e venda da força de trabalho, que pode assumir várias formas, incorporando benefícios sociais e até outras autônomas e/ou informais, cuja característica comum está na desoneração dos custos empresariais.

O trabalho tem sido entendido principalmente como atividade na produção ou prestação de serviços variados. Para Castel (2011, p. 416), o emprego estável e protegido constituiu a base da construção da solidariedade na sociedade salarial. Ou seja, sobre a base das associações profissionais foram montados os sistemas de proteção mutualistas para enfrentamento dos riscos sociais como doença, desemprego, velhice etc. Os sistemas europeus de proteção social, aqui referidos, privilegiavam o lugar ocupado pelos trabalhadores na hierarquia da divisão social do trabalho. Diferenciados e hierarquizados, esses sistemas, em linhas gerais, garantiam a construção de solidariedade a partir da categoria socioprofissional, beneficiando os assalariados em geral. O estatuto de emprego formava a base da economia da solidariedade que compunha a cidadania social. O enfraquecimento das relações de emprego clássico versus formas de atividade (ou ocupação) diversas (com relações idem) poderia no limite levar a uma sociedade de plena atividade, que é distinta de uma sociedade de pleno emprego. Castel busca explicar essa passagem a partir da transição do "salariato" ao "precariato", ou formas atípicas de emprego, marcadas pela precariedade das condições e relações de trabalho, pelo caráter casual, temporário, flexível em sua atividade e acesso à remuneração (2011, p. 416). 
Há outra distinção, que em certa medida complementa a primeira: o termo serviços, ou prestação de serviços, retoma a equivocada e nunca resolvida dualidade: trabalho produtivo - gerador de mercadorias, e, portanto de valor - e trabalho improdutivo - aquelas atividades-meios para a produção propriamente dita, que durante todo o século XX tornaram-se majoritárias em termos de ocupação dos trabalhadores. Estão incluídas aí várias atividades de cuidados (care), produção cultural e artística, prestação de serviços pessoais, ensino, serviços de informática, dentre muitas outras que se desenvolvem rapidamente com as novas demandas sociais. Tais atividades são consumidas, desprovidas de materialidade e não têm como resultado um produto final, mas, sim, um serviço, como a atualização de um software, o corte de cabelo de uma pessoa, a resolução de uma questão demandada por um cliente. O conhecimento e sua produção se incluem nessa 150 imaterialidade ${ }^{6}$ produzindo igualmente mercadorias imateriais caracterizadas pela efemeridade, mas que exigem certa materialidade presente em suas embalagens, em seu hardware, além de outras formas. Essas atividades, embora se diferenciem do trabalho clássico, aproximam-se dele em termos da busca por baixos custos, algo que mantém as relações de subordinação e exploração, a despeito de serem variadas e imprimirem um controle mais fluido do trabalho. Espera-se do trabalhador que atinja determinadas metas, que tenha um comportamento proativo e simpático aos clientes. Estes por sua vez atuam no controle do trabalho, exigindo qualidade e procedimentos. Outra consequência se manifesta na organização difusa dos trabalhadores de serviços e nas características de suas lutas e reivindicações, assim como na construção de novas identidades coletivas.

${ }^{6}$ Sobre o conceito de trabalho imaterial, ver Gorz (2005). 
O debate acerca da solidariedade é retomado visando não apenas os excluídos do mercado de trabalho, ou mesmo aqueles que nunca tiveram acesso a ele, mas também os trabalhadores das novas ocupações nas quais nem sempre o assalariamento é a norma. Essa discussão aparece nas propostas sobre renda mínima que se pretendem universalizantes para garantir um mínimo necessário à subsistência das pessoas, independentemente de vinculação a trabalho ${ }^{7}$, e em políticas sociais focalizadas nos excluídos, os pobres, ou em formas de geração de renda, através de associações e ONGs (terceiro setor) que atuam em parte substituindo o Estado ou complementando sua atuação ${ }^{8}$.

\section{Solidarismo cristão, conflitos e direitos sociais}

Em busca de melhor compreensão da relação entre solidariedade e trabalho, vejamos como tal combinação se fez presente no chamado catolicismo social, que exerceu influência sobre políticas sociais em diversos países ocidentais. Essa matriz religiosa, de origem corporativista, é uma das constituintes do que, no final do século XX, ficou conhecido como economia solidária.

Ao final do século XIX, a Igreja Católica acompanhava tanto o crescimento da desigualdade social, próprio do desenvolvimento do capitalismo industrial, quanto a crescente secularização da sociedade. O socialismo ainda não havia se instituído como um sistema de poder, mas sindicatos e partidos operários se organizavam e lutavam por mudanças, exercendo crescente pressão sobre as elites euro-

\footnotetext{
7 No Brasil, o Projeto de lei sobre Renda Mínima encontra-se em tramitação na Câmara dos Deputados desde 1992.

8 Nos anos 1990, essas políticas sociais focalizadas foram explicitadas no programa Comunidade Solidária, criado em 1995, e que tinha como proposta modernizar a gestão das políticas públicas, integrando e descentralizando as ações do governo em parcerias com a sociedade na busca de soluções para atender as populações mais pobres. O programa pretendia apoiar políticas específicas com esse objetivo.
} 
peias. Foi nesse contexto que o papa Leão XIII promulgou em 1891 a encíclica Rerum Novarum, primeiro documento da igreja voltado para o mundo exterior, enfocando a chamada "questão social"". O texto denunciava a precariedade das condições de vida da classe operária, afirmando ser dever do Estado garantir direitos sociais, assim como reivindicava a liberdade de associação em sindicatos para fazer valer "os legítimos interesses dos trabalhadores”. Há alguma atribuição de culpa ao capitalismo industrial e também uma condenação veemente do socialismo, visto como ameaça à igreja por seu racionalismo e discurso anticlerical e ateu.

Para a igreja, havia se tornado impossível ignorar os conflitos de classe, que a fizeram voltar para fora de si mesma, finalmente se posicionando de alguma maneira frente às contradições e aos conflitos do mundo urbano e industrializado. Procurava estender o alcance de sua doutrina reafirmando antigos valores morais, como a vida em 152 família e em comunidade, por exemplo, com o propósito de reforçar a identidade religiosa, sobretudo do operariado. De modo geral, os bispos repudiavam o ateísmo de viés anarquista e comunista, bem como defendiam o patronato, considerado socialmente responsável e caracterizado na figura do empresário e pai de família exemplar. Ainda que alguns padres isolados se solidarizassem com reivindicações por direitos civis e sociais, o conjunto da igreja prescrevia a obediência e a submissão da classe operária.

O pontificado de Pio XI (1922-1939) foi um dos que ficaram marcados pelo forte conservadorismo político. Através da encíclica Divini Redenptoris (1937), o chefe da igreja condenou oficialmente o socialismo e concedeu apoio a

\footnotetext{
9 Foi durante seu pontificado (1878-1903) que começou a ser formulada a Doutrina Social da Igreja, conjunto de recomendações aos católicos para que eles se preocupassem e promovessem ações voltadas para o que se considera bem-estar social. Compõem a base desse arcabouço outras duas encíclicas papais: Quadragésimo Anno, de Pio XI, 1931, e Mater et Magistra, de João XXIII, 1961 (Oliveira, 2001).
} 
líderes fascistas europeus, sobretudo Benito Mussolini, na Itália, e Francisco Franco, na Espanha. Trabalhou firmemente pela aliança entre Estado e igreja, buscando fortalecer o catolicismo no mundo de secularização crescente. Foi sob seu comando que a instituição organizou o movimento de leigos chamado Ação Católica, com repercussões significativas no Brasil. Com o apoio papal, o cardeal do Rio de Janeiro, dom Sebastião Leme, buscou a inserção da igreja nos principais órgãos de políticas sociais do Estado, mediante a formação de um quadro de intelectuais católicos e a aproximação com Getúlio Vargas, cujo período de governo caracterizou o apogeu da chamada neocristandade brasileira (Mainwaring, 1989, pp. 41-43).

Sob a inspiração da Rerum Novarum, desenvolvia-se na igreja brasileira o debate sobre a questão operária, transformado em reivindicação por um código que disciplinasse as relações de trabalho. A inserção católica militante no governo getulista se deu já em 1930, concomitantemente à criação do Ministério do Trabalho, Indústria e Comércio. Seu corpo técnico, incumbido de formular o Código do Trabalho, era composto, na maioria, por militantes pastorais indicados por Alceu Amoroso Lima, então diretor do Centro Dom Vital e intelectual direitista que, por influência dos filósofos franceses Jacques Maritain e Emanuel Mounier, também aderiu ao catolicismo social (Souza, 2002, pp. 143-57).

A referência ideológica dos intelectuais católicos brasileiros de então era o corporativismo, entendido como forma de "harmonização" de classes sociais através da organização de trabalhadores por categorias profissionais (corporações) em suposta colaboração mútua. Tal concepção tradicionalista de uma "incorporação de trabalhadores pelo alto" representava a dimensão conservadora do catolicismo social, que se integrou à política getulista. $\mathrm{O}$ aspecto progressista da proposta estava na pressão pela implantação de 
uma legislação social, sobretudo previdenciária. Uma face secundária da "terceira via" católica no Brasil se traduziu em iniciativas isoladas de mutualismo e cooperativismo por parte de alguns militantes pastorais.

No meio dessa militância católica de base surgiram os Círculos Operários, grupos que promoviam atividades comunitárias de educação e ajuda mútua e começaram a ser organizados em 1932. Logo, o circulismo operário cresceu e se consolidou como o "braço sindical" da igreja no Brasil. O desenvolvimento desse movimento propiciou a criação em 1937 da Confederação Nacional dos Trabalhadores Cristãos, que foi reconhecida como órgão consultivo do Ministério do Trabalho em 1941. A Confederação publicaria um Código social em 1942, mesmo ano em que o Estado Novo consolidou a legislação trabalhista e institucionalizou a Justiça do Trabalho (Souza, 2002).

Os circulistas preconizavam a participação ativa de 154 seus membros em sindicatos e aspiravam à instauração no país de uma "ordem social cristã", baseada no cumprimento rígido da legislação. Para dar conta de suas tarefas assistenciais, o circulismo criou departamentos de ensino, saúde, beneficência e defesa, cultura e lazer. O movimento visava criar em torno do operariado uma rede de obras assistenciais que propiciasse atendimento médico, jurídico, educacional, religioso e recreativo. Na primeira metade da década de 1940, o circulismo se desenvolveu consideravelmente, estruturando seus departamentos e criando mais um: o cooperativista. No âmbito dos círculos operários, foram formadas algumas cooperativas de produção, consumo e crédito (Souza, 2002, pp. 222-37).

Lideranças circulistas, clérigos e leigos bebiam em outras fontes para levar adiante a proposta cooperativista. Uma delas foi o movimento Economia e Humanismo, formado na França em 1941 por iniciativa do padre dominicano Louis-Joseph Lebret, também influenciado por Jacques 
Maritain (Pelletier, 1996). Paralelamente à origem desse movimento, surgiu no mesmo ano um grupo de operários católicos da cidade francesa de Valence que passou a produzir adotando a forma de autogestão e ficou conhecido como Comunidade de Trabalho Boimondeau (Hofstede, 1994, pp. 170-90; Desroche, 1964). Essa experiência de trabalho inspirou outras comunidades do gênero naquele país, inclusive um padre brasileiro lá residente, também dominicano e participante do movimento Economia e Humanismo: frei João Baptista Pereira dos Santos.

De volta ao Brasil, frei João tornou-se capelão de uma paróquia do bairro paulistano do Ipiranga, onde começou um ambicioso projeto comunitário com nome de Centro Social Cristo Operário (Claro, 2004, pp. 25-26). Nesse centro, junto com o artista plástico Geraldo de Barros, o padre fundou uma empresa que seria a versão brasileira de uma "comunidade de trabalho". A fábrica produzia requintados móveis de madeira, projetados por Barros. Assim nasceu em 1954 a Unilabor, empresa que abrangeu quatro lojas em São Paulo e uma em Belo Horizonte e chegou a ter cerca de cem trabalhadores, entre cooperados e aspirantes.

No contexto internacional dos anos 1950, a Igreja Católica estava diante do dilema de propor algo perante as contradições sociais do capitalismo liberal, capitaneado pelos Estados Unidos e pelo socialismo de Estado, liderado pela então União Soviética. Diante desses dois mundos antagônicos, a instituição começou a esboçar uma proposta de "caminho alternativo". Pregava a valorização da pessoa humana, que supostamente teria sido subtraída de ambos os sistemas de produção econômica e social. O movimento Economia e Humanismo expressava o ideário católico de algo que fosse intermediário ao capitalismo e ao socialismo, tanto no Brasil (Santos, 1964) quanto mundialmente (Camargo et al., 1984, pp. 343-80). Era uma proposta de meio-termo, a propalada "terceira via". O projeto defendia a liberdade individual do 
capitalismo e o princípio da igualdade econômica do socialismo, algo que alguns teóricos católicos chamaram de "solidarismo cristão" (Ávila, 1965). Idealizava-se a organização igualitária do trabalho em comunidades.

Ao criticar capitalismo e socialismo, frei João Baptista apontava uma alternativa "comunitarista" que assumia a forma de cooperativismo de trabalho. Em seus textos, ele propunha a proliferação de comunidades de trabalho, a exemplo da Unilabor, como resposta às contradições do capitalismo no Brasil. Acreditava que as Comunidades Eclesiais de Base (CEBs) ofereciam o ambiente propício para a formação de pequenas empresas de autogestão. No entanto, a saída de alguns trabalhadores, levando suas cotas-parte de capital, e um desentendimento posterior levaram ao fim das atividades da Unilabor em 1967 (Santos, 1982, p. 38).

Enquanto a experiência cooperativista católica malograva no Brasil, outra obtinha êxito na Espanha, iniciando-se 156 no período pós-guerra civil. O atual Complexo Cooperativo de Mondragón surgiu a partir da iniciativa do padre diocesano José María Arizmendiarrieta. Teve apoio do governo central, preocupado com a recuperação econômica do País Basco, destroçado pela guerra civil. Em 1948, o sacerdote conseguiu estruturar e legalizar uma associação de moradores daquela cidade, criando uma unidade de ensino chamada de Escola Politécnica Profissional. Tal escola forneceu a base para a criação e o desenvolvimento do complexo cooperativo, e, em 1956, foi organizada por ex-alunos a primeira cooperativa de produção, chamada Ulgor (hoje Fagor Eletrodomésticos), que inicialmente dedicou-se à fabricação de aquecedores e fogões a gás e hoje é uma das maiores produtoras de eletrodomésticos de linha branca da Europa (Whyte e Whyte, 1988).

As cooperativas de Mondragón não demoraram a crescer e diversificar seu campo de atuação. Ainda na década de 1950, o sacerdote coordenou a interligação das unida- 
des produtivas, organizando também na forma de cooperativa: uma escola (posteriormente uma universidade), um supermercado e um instituto de pesquisa tecnológica. Ele exercia seu sacerdócio, apontando o cooperativismo como a tradução econômica da terceira via católica, algo mal delineado pelas autoridades eclesiásticas. Desenvolveu seu projeto cooperativista sob o regime militar franquista, do início ao fim. Quando o ditador morreu, em 1975, o complexo cooperativo estava sendo organizado para se adequar à reestruturação econômica em curso, buscando ampliar sua participação no mercado espanhol e também de outros países.

O empreendimento de Mondragón se tornou uma multinacional com mais de quarenta mil trabalhadores envolvidos, enfrentando problemas e contradições, embora mantendo a proposta cooperativista (Kasmir, 1996; Azevedo e Gitahy, 2010). Entretanto, não conseguiu replicar o modelo fora do País Basco e mesmo na Espanha, ou seja, não incorporou de fato a proposta cooperativista em suas sucursais ${ }^{10}$.

Ao lado do Estado de bem-estar social europeu, ao qual a Espanha só teve acesso com o fim do franquismo e sua entrada na Comunidade Europeia, a experiência de Mondragón foi analisada como uma forma alternativa de fordismo. As cooperativas aliavam uma gestão mais democrática do trabalho - com as garantias de reprodução social dos trabalhadores no complexo cooperativo - e formas competitivas que inseriram o complexo em mercados internacionais, junto com outros grupos multinacionais (Kasmir, 1996). A experiência cooperativista do País Basco se insere na perspectiva que podemos chamar de corporativista, em que trabalho e solidariedade se complementam, seja na

\footnotetext{
${ }^{10}$ Houve tentativa de tornar uma cooperativa a maior rede de supermercados espanhola, Eroski, do grupo Mondragón. Uma cooperativa produtora de carrocerias de ônibus deixou o complexo, tornando-se uma empresa regular. No resto do mundo, Brasil inclusive, as empresas funcionam de forma convencional, adotando princípios organizativos participativos, na perspectiva do capitalismo flexível.
} 
proposta de autogestão, seja de heterogestão. O diferencial vai aparecer no período posterior, com as reformas neoliberais através das quais o Estado reduziu sua participação na reprodução social, tornando o complexo cooperativo uma forma funcional de administrá-la e transferindo para os trabalhadores o ônus da gestão.

\section{Solidariedade social e economia solidária}

De início, cabe aqui uma distinção conceitual entre a chamada economia social e a economia solidária. A primeira, mais debatida em alguns países europeus, sobretudo França e Espanha, vincula-se a formas cooperativas de organização da produção inseridas no mercado, tendo existido durante todo o século XX, mas com papel secundário na economia. A partir dos anos 1970, principalmente na Espanha e Itália, assumiram papel importante na organização de cooperativas ou na transformação em empreendimentos 158 cooperativos, empresas em dificuldades econômicas, como possibilidade de atenuação do desemprego decorrente dos processos de reestruturação.

Em decorrência disso, surgiram também cooperativas oriundas de processos de terceirização, principalmente na Espanha, organizadas pela igreja e algumas ONGs (Herranz e Hoss, 1990-1991), as sociedades laborales. Trata-se de sociedades anônimas de responsabilidade limitada nas quais a maioria do capital social (51\%) é de propriedade dos trabalhadores que as compõem ${ }^{11}$. As primeiras reuniam mulheres de regiões economicamente periféricas do país, trabalhando sob contrato para grandes redes varejistas. Já as segundas foram criadas como forma de flexibilizar cooperativas e incentivar a abertura de sociedades controladas por trabalhadores, visando apoiar pequenos empreendimentos.

\footnotetext{
${ }^{11}$ Para uma caracterização das sociedades laborales, ver <http://www.empleo.gob. es/es/guia_2_7_4.htm>. Acesso em: 27 dez. 2014.
} 
Na França, o uso do termo economia solidária parte da discussão das relações não mercantis existentes em todas as sociedades e das relações de proximidade, que respondem por parte da produção e do acesso a bens e serviços. Insere-se na discussão sobre o enfraquecimento da sociedade salarial e o desenvolvimento de formas alternativas de organização social, para além das cooperativas, que tenham como cerne um caráter democrático. São ações coletivas diversas, não filantrópicas, mas econômicas, abrangendo clubes de trocas de mercadorias mediante uso de uma "moeda social" própria, autoconstrução coletiva, microcrédito, entre outras formas. Elas teriam em comum o fato de representarem uma nova maneira de regulação social, em tese, democrática (Laville, 1994; Eme e Laville, 1994).

Castel (1998, p. 575) critica essa abordagem, argumentando que a criação de atividades e vínculos entre pessoas, a relação de emprego e coesão social, embora louvável, se limitaria a declarações de intenções, mais do que à adoção de políticas efetivas. Reconhece a expansão dessas atividades, mas questiona o que chama de tratamento "social" do desemprego, sem deixar claro se a proposta será o retorno ao emprego, ou a criação de uma situação intermediária entre trabalho e assistência. Para ele, esse tratamento intermediário se justificaria em situações de crise, mas seria eufemismo chamá-la de política de emprego.

No âmbito brasileiro e latino-americano, podemos nos referir ao surgimento do conceito de economia solidária no amplo debate sobre informalidade, precarização do emprego e da pequena produção familiar. Recupera-se a discussão de um socialismo possível, com Marx e socialistas utópicos, como Saint Simon, tendo como base o trabalho e a propriedade coletiva de unidades de produção que possibilitariam geração de renda e inclusão social (Singer, 2002; Santos, 2002; Coraggio, 2003, Leite, 2009). 
No Brasil, durante as duas últimas décadas, esse debate vinculou-se ao surgimento de um movimento social que agregou diversos setores e outros movimentos como os dos sem-terra, catadores de lixo reciclável, trabalhadores de fábricas recuperadas, contra a fome e a miséria, entre outros, a partir dos anos 1990. O movimento de economia solidária se estruturou com base na proposta de organização de cooperativas e associações voltadas ao combate ao desemprego, à inclusão de jovens, idosos e excluídos do mercado de trabalho, a partir de formas de autogestão de organização do trabalho e da propriedade coletiva dos meios de produção, numa economia diferente, mas integrada ao mercado capitalista (Lima, 2014).

No entanto, a utilização de cooperativas de trabalho com propostas de autogestão foi percebida também como precarização da relação salarial, como o modelo das cooperativas de terceirização que se tornaram comuns no Bra160 sil a partir dos anos 1990 (Lima, 2002). Estas se multiplicaram como forma de redução de custos nos processos de externalização das atividades empresariais e focalização na atividade principal. Foram consideradas, naquela década, uma forma de enfrentamento do chamado "custo Brasil", a partir do discurso do "elevado" custo da contratação de trabalhadores e da necessidade de flexibilização das leis trabalhistas. As chamadas falsas cooperativas foram combatidas por órgãos sindicais e pelo Ministério Público do Trabalho, movidos contra a precarização das relações de trabalho (Lima, 1997).

O enfoque inicial proposto por Singer (1998) de um novo socialismo progressivamente deu lugar ao discurso da inclusão social dos excluídos do mercado, apontando uma forma alternativa de ocupação e geração de renda. Com a recuperação econômica da década de 2000, o aumento dos empregos formais, do salário mínimo e a implementação de políticas sociais compensatórias, as cooperativas deixaram 
de ser uma alternativa ao assalariamento. Gradativamente, o movimento de economia solidária se inseriu nas políticas públicas de governos progressistas em âmbitos municipal, estadual e federal, com a criação em 2003 da Secretaria Nacional de Economia Solidária (Senaes) no então recém-empossado governo Lula. No governo Dilma Rousseff, passou a integrar o Programa Brasil sem Miséria, no qual os empreendimentos de economia solidária aparecem como possível saída dos programas sociais compensatórios, sobretudo o Bolsa Família. Para evitar fraudes, foi aprovada a nova lei do cooperativismo de trabalho em junho de 2012, que regulou a abertura e o funcionamento dessas cooperativas, de modo a evitar as tentativas de utilização desse formato de organização como forma de precarização das relações de trabalho (Lima, 2014).

Na retomada do debate sobre solidariedade, agora na perspectiva (embora não exclusiva) da economia solidária, há a junção de referências diversas, tais como o socialismo utópico, traços do marxismo, o solidarismo cristão, o princípio da dádiva, de Mauss (1988), e a pluralidade de mercados de Polanyi (2000). Essas referências aparecem nas distintas entidades que integram o movimento, dentre as quais sobressaem a universitária Rede de Incubadoras de Cooperativas Populares, a Agência de Desenvolvimento Solidário (ADS) e a Central de Cooperativas e Empreendimentos Solidários (Unisol), ligadas à Central Única dos Trabalhadores, e Cáritas, vinculada à Conferência Nacional dos Bispos do Brasil (CNBB). Esta última, já no início da década de 1980, havia formado "projetos alternativos comunitários". Esses pequenos empreendimentos econômicos se multiplicaram nacionalmente fazendo com que a Cáritas constituísse a principal entidade não estatal de apoio à economia solidária no país (Bertucci e Silva, 2003; Souza, 2013).

Em tal debate, no qual as cooperativas e associações aparecem como proposta de inclusão e/ou emancipação, de for- 
ma progressiva ou ainda paliativa, destaca-se a tentativa de preservar a regulação moral presente formalmente no ideário cooperativista no sentido de equidade, formação, distribuição e criação de uma cultura própria. Trata-se da proposta de criação de uma alternativa de solidariedade social.

\section{$* * *$}

Fizemos este percurso histórico-analítico no sentido de discutir a retomada do conceito de solidariedade social, tendo como ponto de partida o corporativismo impulsionado por governos, organizações profissionais e pela Igreja Católica, como algo que se manteve até o surgimento, no final do século passado, do chamado capitalismo flexível. Destacamos a passagem do solidarismo cristão para uma nova forma de solidariedade, traduzida em economia solidária, cuja influência católica prossegue marcante, desta vez 162 através da entidade internacional Cáritas.

Procuramos apontar também elementos relevantes para a compreensão da inserção desse debate no contexto europeu do novo papel do Estado e da construção de novos modos de solidariedade. Estas não estariam mais vinculadas ao trabalho, entendido como emprego regular da sociedade salarial, mas, sim, como algo generalizado a todos os cidadãos, através de políticas de renda mínima e acesso a bens sociais e políticas de ocupação dirigidas a populações vulneráveis. Esse debate se fez presente no Brasil no contexto neoliberal dos anos 1990, quando se discutia a focalização das políticas sociais, especialmente a renda mínima, pois apenas uma parcela populacional usufruía de uma condição salarial como sinônimo de acesso a direitos dos cidadãos.

Na década seguinte, as mudanças representadas pelos governos petistas e a retomada do crescimento econômico direcionaram a discussão para as políticas sociais e o refor- 
ço do emprego formal. Não se trata de acesso pleno a direitos, algo que nunca houve por aqui, porém dentro do que Castel chama de "zona cinzenta do assalariamento", ou seja, relações salariais formalizadas, mas não necessariamente estáveis ou vinculadas a direitos. Variações do assalariamento num contexto de capitalismo flexível em que o Estado procura de algum modo fazer valer o princípio da solidariedade, mas se espera que os trabalhadores assumam sua responsabilidade, que sejam empreendedores e empregadores de si mesmos, assumindo, em grande medida, os custos de sua reprodução social.

Tal quadro, no entanto, é contraditório. Assistimos nas duas últimas décadas à recuperação salarial de diversas categorias profissionais, assim como à capacidade organizativa de várias delas. Vimos também a organização de segmentos voltados a novos setores econômicos de prestação de serviços, o que permite inferir sobre a potencialidade dos movimentos reivindicativos e suas conquistas, se considerarmos um quadro de crescimento instável, mas continuado.

Com isso, podemos dizer que há expectativas de reconstituição de modos de solidariedade nos quais o acesso aos bens sociais seja universalizado. Fica a questão, entretanto, da vinculação da solidariedade social ao trabalho ou à atividade econômica, seja em formas tradicionais, seja alternativas, nas quais se incluem os empreendimentos de economia solidária. Retomando Castel (1998), permanece na economia solidária uma situação intermediária entre emprego e assistência, algo que, no caso brasileiro, tende cada vez mais a ser visto como "porta de saída" da assistência para o emprego.

Vale destacar que, para além das questões de ordem econômica e corporativa, presentes nas novas solidariedades em construção na atual fase do capitalismo, as propostas de economia solidária destacam uma moral que constitui elemento de coesão e integração social, apontando para uma 
ordem alternativa. Nessa situação, tanto a inclusão social quanto os traços de emancipação presentes na proposta de economia solidária estão vinculados a fortes elementos de solidariedade que não pressupõem rupturas, mas uma convivência de formas alternativas de inserção econômica, um certo reformismo em busca de um novo modelo de coesão social, a partir de valores morais fortemente marcados pelo associativismo e pela autogestão do trabalho.

A moral, entendida por Durkheim como regras de conduta na busca de um bem comum, está presente nos princípios cooperativistas de Rochadale, atualizados pela Aliança Internacional de Cooperativas, nos quais a adesão livre e voluntária se soma ao controle democrático das atividades por seus membros, pela educação continuada e pela preocupação com a comunidade. Esses princípios são reforçados na proposta de economia solidária definida pela Senaes como "um jeito diferente de produzir, vender, comprar e 164 trocar o que é preciso para viver. Sem explorar os outros, sem querer levar vantagem, sem destruir o ambiente. Cooperando, fortalecendo o grupo, cada um pensando no bem de todos e no próprio bem”. Destacando as atividades econômicas pela participação democrática, a posse coletiva e a distribuição dos ganhos, propõe-se um novo modelo de desenvolvimento sustentável, propiciando trabalho digno e geração de renda, procurando respeitar o meio ambiente, as diferenças de gênero, raça e idade, considerando o homem como centro e finalidade da atividade econômica e se opondo à lógica capitalista da força de trabalho como capital variável e fator de produção. Proposta ambiciosa, mais uma possibilidade do que realidade efetiva dos empreendimentos que se definem como tal.

Mesmo numa perspectiva alternativa, o trabalho continua no centro da construção de novas solidariedades, não mais corporativas e limitadas a grupos profissionais, o que refletiu a fase anterior do capitalismo industrial, mas mantendo no 
capitalismo flexível o trabalho como condição de inserção e integração social. Ao assalariamento juntam-se formas distintas de organização do trabalho. Talvez um novo contrato social, embora ainda incipiente e por ora apenas delineado.

\section{Jacob Carlos Lima}

é professor do Departamento de Sociologia da Universidade Federal de São Carlos (UFSCar), coordenador do Laboratório de Estudos sobre Trabalho, Profissões e Mobilidades e pesquisador do Conselho Nacional de Desenvolvimento Científico e Tecnológico $(\mathrm{CNPq})$.

\section{André Ricardo de Souza}

é professor adjunto do Departamento de Sociologia e do Programa de Pós-Graduação em Sociologia da UFSCar, coordenador do Núcleo de Estudos de Religião, Economia e Política e da Associação Brasileira de Pesquisadores de Economia Solidária.

\section{Bibliografia}

ÁVILA, F. B. 1965. Solidarismo. 3. ed. Rio de Janeiro: Agir.

AZEVEDO, A. B. A.; GITAHY, L. 2010. "The Cooperative Movement, self-management, and cooperativeness: the case of Mondragón Corporación Cooperativa”. Working USA: The Journal of Labor and Society, n. 13 , pp. 5-29

BERTUCCI, A. A.; SILVA, R. M. A. 2003. 20 anos de economia popular solidária: trajetória da Cáritas Brasileira dos PACs à EPS. Brasília: Cáritas Brasileira.

BRAGA, R. 2003. A nostalgia do fordismo: modernização e crise na teoria da sociedade salarial. São Paulo: Xamã.

BRASIL. Ministério do Trabalho e Emprego. Economia solidária. Disponível em: <http://www.portal.mte.gov.br/ecosolidaria/a_economia_ solidaria_no_ministerio_do_trabalho_e_emprego.htm $>$. Acesso em: 27 dez. 2014.

BRAVERMAN, H. 1981. Trabalho e capital monopolista. A degradação do trabalho no século XX. Rio de Janeiro: Zahar.

CAMARGO, C. P. F.; SOUZA, B. M.; PIERUCCI, A. F. 1984. "A Igreja 
Católica: 1945-70”. In: FAUSTO, B. (org.). História geral da civilização brasileira. São Paulo: Difel. v. 11.

CATTANI, A. D.; LAVILLE J.L; GAIGER, L. I.; HESPANHA, P. (orgs.). 2009. Dicionário internacional da outra economia. Coimbra: Almedina.

CASTEL, R. 1998. As metamorfoses da questão social: uma crônica do salário. Petrópolis: Vozes.

2011 [2007]. "Au-delà du salariat ou em deçà de l'emploi?

L’institutionnalisation du précariat”. In: PAUGAM, S. (org.). Repenser la solidarieté. Paris: Press Universitaire de France.

CASTELLS, M.1999. A sociedade em rede. Rio de Janeiro: Paz e Terra.

CLARO, M. 2004. Unilabor: desenho industrial, arte moderna e autogestão operária. São Paulo: Senac.

CORAGGIO, J. L. 2003. Política social y economía del trabajo. Zinacantepec:

El Colegio Mexiquense.

DESROCHE, H. 1964. Coopération et développement: mouvements coopératifs et stratégie du développement. Paris: Presses Universitaires de France.

DURKHEIM, E. 2010 [1930]. Da divisão do trabalho social. 4. ed. São Paulo: Martins Fontes.

EME, B.; LAVILLE, J. L. (orgs.) 1994. Cohésion sociale et emploi. Paris: Desclée de Brouwer.

166 ESPING-ANDERSEN, G. 1991. "As três economias políticas do Welfare State". Lua Nova, n. 24, pp. 85-116.

GIDDENS, A. 1998. Política, sociologia e teoria social. Encontros com o pensamento social clássico. São Paulo: Unesp.

GORZ, A. 2005. O imaterial. Conhecimento, valor e capital. São Paulo: Annablume.

HARVEY, D. 1993. Condição pós-moderna. São Paulo: Loyola.

HERRANZ, R.; HOSS, D. 1990-1991. "División del trabajo entre centro y periferia: cooperativas y industrialización difusa en Galicia”. Sociologia del Trabajo, n. 11, pp. 67-92.

HOFSTEDE, G. 1994. Uncommon sense about organizations: cases, studies, and field observations (case study: Communauté de Travail Boimondau). London: Sage.

KASMIR. S. 1996. The Myth of Mondragón: cooperatives, politics and working-class life in a Basque Town. Albany: State University of New York Press.

LAVILLE, J. L. (org.) 1994. L'économie solidaire: une perspective internationale. Paris: Desclée de Brouwer.

LEITE, M. P. 2009. "A economia solidária e o trabalho associativo: teorias e realidades”. Revista Brasileira de Ciências Sociais, v. 24, n, 69, pp. 31-51. 
LIMA, J. C. 1997. "Negócios da China: a nova industrialização do Nordeste”. Novos Estudos Cebrap, São Paulo, n. 49, pp. 141-58. . 2002. As artimanhas da flexibilização: trabalho flexível em cooperativas de produção. São Paulo: Terceira Margem. . 2014. "Economia solidária: de movimento social a política pública". In: LEITE, M. L.; ARAÚJO, A. M. C.; LIMA, J. C. O trabalho na economia solidária: entre precariedade e emancipação. São Paulo: Annablume.

MAINWARING, S. 1989. Igreja Católica e política no Brasil: 1916-1985. São Paulo: Brasiliense.

MARX, K. 1975. O capital. Crítica da economia política. Rio de Janeiro: Civilização Brasileira.

MARX, K.; ENGELS, F. 1968. O Manifesto do Partido Comunista. São Paulo: Escriba.

MAUSS, M. 1988. Ensaio sobre a dádiva. Lisboa: Edições 70.

MÉDA, D. 1999. O trabalho. Um valor em vias de extinção. Lisboa: Fim de Século.

OFFE, C. 1989. "Trabalho: a categoria chave da sociologia?”. Revista Brasileira de Ciências Sociais, v. 4, n. 10, pp. 5-20.

OLIVEIRA, V. 2001. Evolução da doutrina social da igreja: histórico do pensamento dos papas e dos bispos do Brasil de Leão XIII a Pio XII em relação à questão social, ao capitalismo e ao socialismo. Dissertação de mestrado em História. São Paulo: Universidade de São Paulo.

OLIVEIRA, P. S. 2003. "Uma fonte de solidariedade: a divisão do trabalho social em Durkheim”. In: SOUZA, A. R.; DAKUZKU, R. Y.; CUNHA, G. C. (orgs.). Uma outra economia é possível: Paul Singer e a economia solidária. São Paulo: Contexto.

ORTELLADO, P. 2003. "Mondragón e os impasses do cooperativismo". In: SOUZA, A. R.; DAKUZKU, R. Y.; CUNHA, G. C. (orgs.) Uma outra economia é possível: Paul Singer e a economia solidária. São Paulo: Contexto.

PAUGAM, S. 2011a [2007]. "Introduction: les fondements de la solidarité”. In: PAUGAM, S. (org.). Repenser la solidarité. Paris: Presses Universitaires de France. . 2011b [2007]. "Préface à l'édition Quadrige: renforcer la conscience de la solidarité”. In: PAUGAM, S. (org.). Repenser la solidarité. Paris: Presses Universitaires de France.

PAUGAM, S. (org.). 2011c [2007]. Repenser la solidarité. Paris: Presses Universitaires de France.

PELLETIER, D. 1996. Économie et humanisme: de l'utopie communautaire au combat pour le tiers-monde (1941-1966). Paris: Cerf. 
POLANYI, K. 2000. A grande transformação. Rio de Janeiro: Campus. RIFKIN, J. 1995. O fim dos empregos: o declínio inevitável dos níveis dos empregos e a redução da força global de trabalho. São Paulo: Makron Books.

SANTOS, B. S. (org.). 2002. Produzir para viver: os caminhos da produção não capitalista. Rio de Janeiro: Civilização Brasileira.

SANTOS, J. B. P. 1964. Os chifres do diabo: capitalismo - comunismo. São Paulo: Sal. 1982. Uma saída para o desemprego: comunidade de trabalho na cidade ou no campo. Petrópolis: Vozes.

SINGER, P. 1998. Uma utopia militante: repensando o socialismo. Petrópolis: Vozes. 2002. Introdução à economia solidária. São Paulo: Fundação Perseu Abramo.

SINGER, P.; SOUZA, A. R. (orgs.). 2000. A economia solidária no Brasil: a autogestão como resposta ao desemprego. São Paulo: Contexto.

SOUZA, A. R. 2013. Os laços entre igreja, governo e economia solidária. São Carlos: EdUFSCar/Fapesp.

SOUZA, J. J. V. 2002. Círculos operários: a Igreja Católica e o mundo do trabalho no Brasil. Rio de Janeiro: UFRJ.

168 WEBER, M. 2004. A ética protestante e o espírito do capitalismo. São Paulo: Companhia das Letras.

WHYTE, W. F.; WHYTE, K. K. 1988. Making Mondragón: the growth and dynamics of the Worker Cooperative Complex. Ithaca: ILR Press. 


\section{TRABALHO, SOLIDARIEDADE SOCIAL E ECONOMIA SOLIDÁRIA}

JACOB CARLOS LIMA

\section{ANDRÉ RICARDO DE SOUZA}

Resumo: Este artigo propõe a discussão da solidariedade social, tendo como referência as transformações capitalistas das últimas décadas do século XX e o surgimento de formas alternativas de geração de renda, fora das relações de assalariamento formal, que estruturaram políticas sociais inclusivas. Tendo como referência o movimento de economia solidária no Brasil, abordamos algumas questões fundamentais do debate sobre a construção da solidariedade social que a configurou: o coletivismo laico e o católico, o Estado de Bem-Estar Social, a crise do trabalho e da chamada sociedade salarial.

Palavras-chave: Trabalho; Solidariedade Social; Políticas Sociais; Solidarismo Cristão; Economia Solidária.

\section{WORK, SOCIAL SOLIDARITY AND SOLIDARITY ECONOMY}

Abstract: This paper purposes a discussion about social solidarity, having as reference the capitalist transformations in the last decades of the 20th century as well as the appearing of alternative forms of income generating out of the salary formal relationships, which have structured the inclusive social policies. Having the solidarity economy movement in Brazil as reference, we face a some fundamental issues of the debate about the social solidarity building embraces: the secular and the Catholic collectivism, the Welfare State, the crisis of work and the so-called wage-based society.

Keywords: Work; Solidarity; Social Policies; Christian Solidarism; Solidarity Economy. 